\begin{tabular}{|cc|}
\hline REFINERY & PETROL \\
OLEFINES & PROPORTIONS \\
HEXENES & HEPTENES \\
ISOMERS & SEPARATION \\
ANALYSIS & GC-MS \\
\hline
\end{tabular}

Open access accepted manuscript version of

Chromatographia 38 (1994) 222-226

Link to publisher

\title{
Characterization of sixty alkenes in a cat-cracked gasoline naphtha by gas chromatography
}

Olle Ramnäs, Ulf Östermark and Göran Petersson

Applied analytical studies including alkenes from gasoline:

Urban air near traffic

Road tunnels

Gasoline vapors 
Characterization of Sixty Alkenes in a Cat-cracked Gasoline Naphtha by Gas Chromatography

O. Ramnäs / U. Östermark / G. Petersson*

Department of Chemical Environmental Science, Chalmers University of Technology, 41296 Göteborg Sweden 


\section{Key Words}

Gas chromatography - mass spectrometry

Light FCC naphtha

$\mathrm{C}_{5}-\mathrm{C}_{7}$ Alkene composition

Alkene retention data

\section{Summary}

The alkene-rich petrol fraction from refinery fluid catalytic cracking (FCC) has been characterized by GC and GC-MS. Quantitative proportions and retention data of 52 acyclic and 11 cyclic $\mathrm{C}_{5}-\mathrm{C}_{7}$ alkenes are given. Relative retentions are reported for methylsilicone and aluminium oxide stationary phases as methylene units (MU). Applications of mass spectra, single-ion GC-MS monitoring and retention data for identifications are demonstrated.

\section{Introduction}

Alkenes give rise to photooxidants in rapid atmospheric reactions which differ considerably even between different isomers [1]. Major anthropogenic emissions of volatile alkenes are due to petrol-fuelled vehicles [2]. Speciated determinations of alkenes are therefore of interest not only in air pollution studies but also in refinery, fuel and motor technology $[3,4]$. 
In contrast to the combustion-formed short-chain alkenes, the $\mathrm{C}_{5}-\mathrm{C}_{7}$ alkenes in exhaust emissions from vehicles are mainly unburnt fuel components [2]. They originate predominantly from the light FCC naphtha fraction of the petrol [3]. Most studies of alkenes in fuels [3], emissions [2], and urban air [5] have been limited to $\mathrm{C}_{5}$ and lower alkenes, because of the large number and isomeric complexity of $\mathrm{C}_{6}$ and higher alkenes. In previous reports, the pentenes [6] and the 17 isomeric acyclic hexenes [7] were studied in petrol vapour. The analysis of a FCC naphtha permits the acquisition of more comprehensive alkene data of chromatographic, environmental as well as technical relevance.

\section{Experimental}

Light FCC naphtha, produced from desulphurized vacuum gas oil, was obtained from the Scanraff refinery in Lysekil; Sweden. The naphtha contained hydrocarbons in the boiling point range $20-140{ }^{\circ} \mathrm{C}$. At the refinery it is used as a major component in the production of commercial petrol.

The methylsilicone GC data refer to a DB-1 stationary phase on a $50 \mathrm{~m} \times 0.32 \mathrm{~mm}$ i.d. fused silica open tubular column (J\&W) with a thick $(1 \mu \mathrm{m})$ phase layer. The linear temperature increase was $2{ }^{\circ} \mathrm{C} \mathrm{min}-1$ from $-20^{\circ} \mathrm{C}$. The aluminium oxide GC 
data were obtained for an $\mathrm{Al}_{2} \mathrm{O}_{3} / 5 \% \mathrm{KCl}$ phase on a $50 \mathrm{~m} \mathrm{x}$ $0.32 \mathrm{~mm}$ i.d. fused silica PLOT column (Chrompack). The linear temperature increase was $2{ }^{\circ} \mathrm{C} \min ^{-1}$ from $100{ }^{\circ} \mathrm{C}$ after a rapid initial temperature increase. Helium was used as carrier gas with a linear gas velocity of the order of $20 \mathrm{~cm} \mathrm{~s}^{-1}$.

The FCC naphtha was analysed as both liquid samples and as gaseous samples taken with a syringe above the liquid phase. Adsorbent sampling in a vessel with completely evaporated naphtha, followed by thermal desorption and gas chromatography, was also used to obtain data for the alumina column. Similar techniques were previously used for the analysis of petrol vapour hydrocarbons [6] including hexenes [7], on the same column but with different temperature programs. Quantitative GC data were obtained with flame ionization detection without corrections for response differences between the hydrocarbons.

The mass spectrometer was a Varian Saturn II ion trap GC-MS instrument. The columns and the chromatographic data were similar and comparable for the GC and the GC-MS studies of the naphtha. The scan range was $m / z \quad 35-200$ and the scan frequency was one scan per second. Reconstructed mass spectra and ion chromatograms were obtained from the data-stored 
scans. Reference spectra of most of the $\mathrm{C}_{5}-\mathrm{C}_{7}$ alkenes were available for comparison from the data-stored library (NIST) of mass spectra.

\section{Results and discussion}

\section{Alkenes in the FCC naphtha}

In Table I, the hydrocarbon composition is given for the light FCC naphtha studied. The results were obtained from GC analysis. It is seen that the total proportion of acyclic and cyclic alkenes was just over $40 \%$. A control sample obtained one year later contained somewhat smaller amounts of alkenes and significantly smaller amounts of cycloalkenes and alkadienes. The proportions of different hydrocarbon classes are known to depend on operational parameters and may differ considerably, particularly between different refineries [3]. The proportions between isomers are more uniform, as previously discussed for hexenes [7].

In Table II, results are given for all pentenes and hexenes, and for all heptenes constituting more than $0.1 \%$ of the total $\mathrm{C}_{5}-\mathrm{C}_{7}$ alkenes. All acyclic $\mathrm{C}_{5}-\mathrm{C}_{7}$ alkenes are within the boiling point range $20-100^{\circ} \mathrm{C}$. As expected, the proportions in the gas phase differ from those in the liquid phase according to volatility as reflected by the boiling points. Unbranched isomers and 
isomers which are methyl-branched at the double bond predominate among the non-cyclic alkenes. The most prominent single isomers are the 2-methyl-2-alkenes. Among the $\mathrm{C}_{6}-\mathrm{C}_{7}$ cycloalkenes, the most prominent isomers are branched at the double bond.

\section{Retention data}

Relative retentions for linear temperature-programmed analysis are given in Table II as methylene units (MU), corresponding to the retention index defined for isothermal analysis. Relative retentions depend to some extent on temperature, and consequently $\mathrm{MU}$ values depend on the temperature program. A linear temperature increase starting from a low temperature was chosen for both the methylsilicone and the alumina columns to give MU values of wide applicability. As a result, the MU difference between an alkene and the next higher homologous alkene is near to 1.0 which may facilitate and confirm identifications.

The alkene isomers in Table II have been ordered according to increasing retention on the methylsilicone column. The retention order of the isomers closely follows the order of increasing boiling points. The trans isomers which are unbranched at the olefinic ( $\alpha$ ) carbon atoms are somewhat less retained than their boiling points might suggest. 
On the methylsilicone column, the alkenes appear in the same MU range as the corresponding alkanes, although the dependence of retention order on isomer structure is different. Not only unbranched but also $\alpha$-branched alkene isomers appear later than other branched alkene isomers. Branching at non-olefinic carbon atoms decreases retention as with alkanes, and B-branching causes a specific further decrease. The 1-alkene isomers appear before the corresponding 2- and 3alkenes. The reported MU values compare well with published retention index data for several alkenes $[8,9]$ on methylsilicone phases.

On the polar alumina column, the alkenes are retained more strongly than the corresponding alkanes. On the other hand, the MU range for each group of alkene isomers is smaller than for the methylsilicone. Several retention characteristics can be ascribed to steric hindrance of interactions between the double bond of the alkenes and the polar stationary phase. Branching at an olefinic carbon atom decreases retention, particularly for internal alkenes. The trans isomers which are unbranched at the olefinic carbon atoms appear before $(\sim 0.2 \mathrm{MU})$ the $c i s$ isomers. The 1-alkenes are rather more strongly retained than the corresponding 2- and 3-alkenes. These MU shifts cause the retention order of isomeric alkenes to be quite different from that on the methylsilicone phase. The effects of branching at the 
non-olefinic carbon atoms are similar for both stationary phases, however.

\section{Gas chromatography and mass spectrometry}

The chromatograms given in Figure 1 illustrate the usefulness of GC-MS for the separation and identification of alkenes in FCC naphtha. Hexanes and hexenes appear in the same chromatographic range on the non-polar column. The $\mathrm{m} / \mathrm{z} 67$ ion chromatogram specifically records the three methylcyclopentenes, although they are all unresolved from other prominent hydrocarbons. The co-elution of 1-methylcyclopentene with benzene on methylsilicone columns may easily be overlooked, although this danger has been emphasized for standardized determinations of benzene [10]. A previous comparable GC-MS study of hexenes demonstrates the performance of the alumina column [7].

For structural identifications, the mass spectra of the reported $\mathrm{C}_{5}-\mathrm{C}_{7}$ alkenes were compared with reference spectra and interpreted with respect to mass spectrometric fragmentation. Observed peaks considered to be of particular value for structural assignments are indicated in Table II by their $\mathrm{m} / \mathrm{z}$ values. Most of the alkenes exhibit characteristic peaks at even mass numbers from their molecular ions. Many isomers give rise to abundant odd-mass ions by allylic cleavage of the 
molecular ion with loss of an alkyl radical. Hydrogen rearrangements with loss of an alkene moiety result in specific even-mass peaks, particularly for several 1-alkenes. In spite of these specific fragmentations, the mass spectra of several isomers are very similar, and retention data from the two GC columns were needed for final structural assignments.

\section{References}

[1] R. Atkinson, Atmos. Environ. 24A, 1 (1991).

[2] J. Bailey, S. Eggleston, Sci. Total. Environ. 134, 263 (1993).

[3] E. Pescarollo, R. Trotta, P. R. Sarathy, Hydrocarbon process. 72, 53 (1993).

[4] E. W. Kaiser, W. O. Siegl, Y. I. Henig, R.W. Anderson, F. H. Trinker, Environ. Sci. Technol. 25, 2005 (1991).

[5] G. Barrefors, G. Petersson, J. Chromatogr. 643, 71 (1993).

[6] U. Östermark, G. Petersson, Chemosphere 25, 763 (1992).

[7] O. Ramnäs, U. Östermark, G. Petersson, J. Chromatogr. 638, 65 (1993)

[8] S. Boneva, N. Dimov, Chromatographia 21, 149 (1986).

[9] C. M. White, J. Hackett, R. R. Anderson, S. Kail, P. S. Spock, J. High Resolut. Chromatogr. 15, 105 (1992).

[10] R. E. Pauls, G. J. Weight, P. S. Munowitz, J. Chromatogr. Sci. 30, 32 (1992). 
Table I The FCC naphtha characterized by its composition (\%, w/w) of hydrocarbon categories*.

\begin{tabular}{|c|c|c|c|c|c|c|c|}
\hline & Total & $\mathrm{C}_{4}$ & $\mathrm{C}_{5}$ & $\mathrm{C}_{6}$ & $\mathrm{C}_{7}$ & $\mathrm{C}_{8}$ & $\mathrm{C}_{9}$ \\
\hline Alkanes & 29.6 & 0.1 & 9.6 & 8.8 & 5.6 & 3.5 & 2.0 \\
\hline Alkenes & 31.7 & 0.6 & 13.6 & 10.4 & 5.8 & 1.3 & - \\
\hline Alkadienes & 0.7 & - & 0.3 & 0.4 & - & - & - \\
\hline Cycloalkanes & 9.2 & - & 0.2 & 2.8 & 3.7 & 2.5 & - \\
\hline Cycloalkenes & 6.8 & - & 0.7 & 2.2 & 2.4 & 1.5 & - \\
\hline Cycloalkadienes & 0.3 & - & 0.1 & 0.2 & - & - & - \\
\hline Arenes & 14.7 & - & - & 1.0 & 4.3 & 6.7 & 2.7 \\
\hline
\end{tabular}

*The results were obtained by appropriate summing of 120 identified hydrocarbons (89\% of the naphtha) and additional compounds (4\% of the naphtha) identified only as to structural class. The remaining portion of the naphtha consists mainly of about $1 \%$ each of $\mathrm{C}_{8}-\mathrm{C}_{10}$ alkanes, $\mathrm{C}_{8}-\mathrm{C}_{9}$ alkenes, $\mathrm{C}_{7}-\mathrm{C}_{9}$ alkadienes, $\mathrm{C}_{8}-\mathrm{C}_{9}$ cycloalkanes, $\mathrm{C}_{8}-\mathrm{C}_{9}$ cycloalkenes and $\mathrm{C}_{9}-\mathrm{C}_{10}$ arenes. 
Table II. Analytical data for $\mathrm{C}_{5}-\mathrm{C}_{7}$ alkenes in the FCC naphtha.*

\begin{tabular}{|c|c|c|c|c|c|c|}
\hline \multirow[t]{2}{*}{ Alkenes } & \multicolumn{2}{|c|}{ Relative proportions } & \multirow{2}{*}{$\begin{array}{l}\text { Boiling } \\
\text { point } \\
{ }^{\circ} \mathrm{C}\end{array}$} & \multicolumn{2}{|c|}{ Relative retentions } & \multirow{2}{*}{$\begin{array}{c}\text { Specific } \\
\text { MS ions } \\
m / z\end{array}$} \\
\hline & $\begin{array}{c}\text { Liquid } \\
\%\end{array}$ & $\begin{array}{l}\text { Gas } \\
\%\end{array}$ & & $\begin{array}{c}\text { Methylsilicone } \\
\text { MU } \\
\end{array}$ & $\begin{array}{c}\mathrm{Al}_{2} \mathrm{O}_{3} / \mathrm{KCl} \\
\mathrm{MU} \\
\end{array}$ & \\
\hline C5 Acyclic & 39.0 & 71.1 & & & & \\
\hline 3-Methyl-1-butene & 0.8 & 2.9 & 20.1 & 4.50 & 5.24 & 70,55 \\
\hline 1-Pentene & 3.7 & 8.6 & 30.0 & 4.86 & 5.41 & 70,42 \\
\hline 2-Methyl-1-butene & 6.5 & 14.4 & 31.2 & 4.95 & 5.43 & 70,55 \\
\hline$E$-2-Pentene & 9.9 & 16.4 & 36.4 & 5.08 & 5.29 & 70,55 \\
\hline Z-2-Pentene & 5.4 & 9.4 & 36.9 & 5.15 & 5.50 & 70,55 \\
\hline 2-Methyl-2-butene & 12.7 & 19.4 & 38.5 & 5.19 & 5.38 & 70,55 \\
\hline C6 Acyclic & 29.6 & 17.6 & & & & \\
\hline 3,3-Dimethyl-1-butene & 0.1 & 0.1 & 41.2 & 5.12 & 6.05 & 84,69 \\
\hline 4-Methyl-1-pentene & 0.6 & 0.5 & 53.9 & 5.54 & 6.29 & 84,43 \\
\hline 3-Methyl-1-pentene & 0.8 & 0.6 & 54.2 & 5.55 & 6.19 & 84,69 \\
\hline 2,3-Dimethyl-1-butene & 0.7 & 0.6 & 55.6 & 5.64 & 6.23 & 84,69 \\
\hline Z-4-Methyl-2-pentene & 0.5 & 0.4 & 56.4 & 5.66 & 6.20 & 84,69 \\
\hline E-4-Methyl-2-pentene & 1.5 & 1.1 & 58.6 & 5.69 & 6.05 & 84,69 \\
\hline 2-Methyl-1-pentene & 2.6 & 1.7 & 62.1 & 5.87 & 6.42 & 84,56 \\
\hline 1-Hexene & 1.5 & 0.9 & 63.5 & 5.88 & 6.45 & 84,56 \\
\hline 2-Ethyl-1-butene & 0.9 & 0.5 & 64.7 & 5.99 & 6.39 & 84,69 \\
\hline E-3-Hexene & 1.9 & 1.2 & 67.1 & 6.02 & 6.23 & 84,55 \\
\hline Z-3-Hexene & 0.8 & 0.5 & 66.4 & 6.03 & 6.43 & 84,55 \\
\hline E-2-Hexene & 4.0 & 2.2 & 67.9 & 6.05 & 6.30 & 84,55 \\
\hline 2-Methyl-2-pentene & 4.3 & 2.5 & 67.3 & 6.07 & 6.25 & 84,69 \\
\hline Z-3-Methyl-2-pentene & 2.5 & 1.4 & 67.7 & 6.10 & 6.28 & 84,69 \\
\hline Z-2-Hexene & 2.2 & 1.2 & 68.9 & 6.14 & 6.50 & 84,55 \\
\hline E-3-Methyl-2-pentene & 3.8 & 1.8 & 70.4 & 6.20 & 6.29 & 84,69 \\
\hline 2,3-Dimethyl-2-butene & 0.9 & 0.4 & 73.2 & 6.30 & 6.23 & 84,69 \\
\hline C7 Acyclic & 16.4 & 5.0 & & & & \\
\hline 2,4-Dimethyl-1-pentene & 0.2 & 0.1 & 81.6 & 6.46 & $7.14^{*}$ & 56 \\
\hline 3-Methyl-1-hexene & 0.1 & 0.0 & 83.9 & 6.50 & 7.20 & 70,69 \\
\hline 2-Ethyl-3-methyl-1-butene & 0.1 & 0.0 & 86.4 & 6.52 & $7.14^{*}$ & 98,83 \\
\hline 2,4-Dimethyl-2-pentene & 0.3 & 0.1 & 83.3 & 6.55 & 6.97 & 98,83 \\
\hline 5-Methyl-1-hexene & 0.1 & 0.0 & 85.3 & 6.57 & 7.35 & 56 \\
\hline 2,3-Dimethyl-1-pentene & 0.3 & 0.1 & 84.3 & 6.58 & 7.14 & 98,69 \\
\hline E-2-Methyl-3-hexene & 0.5 & 0.2 & 85.9 & 6.61 & 6.95 & 98,69 \\
\hline 4-Methyl-1-hexene & 0.1 & 0.0 & 86.7 & 6.64 & 7.28 & 57,56 \\
\hline E-4-Methyl-2-hexene & 0.6 & 0.2 & 87.6 & 6.66 & 6.92 & 98,69 \\
\hline Z-4-Methyl-2-hexene & 0.3 & 0.1 & 86.3 & 6.66 & 7.13 & 98,69 \\
\hline Z-2-Methyl-3-hexene & $0.2^{*}$ & 0.1 & 86.1 & 6.67 & 7.12 & 98,69 \\
\hline E-5-Methyl-2-hexene & $0.6^{*}$ & 0.2 & 88.1 & 6.69 & 7.15 & 98,56 \\
\hline Z-3,4-Dimethyl-2-pentene & 0.2 & 0.1 & 89.3 & 6.79 & 7.11 & 98,83 \\
\hline Z-5-Methyl-2-hexene & 0.3 & 0.1 & 89.5 & 6.80 & 7.36 & 98,56 \\
\hline 2-Methyl-1-hexene & 0.9 & 0.3 & 92.0 & 6.86 & 7.42 & 56 \\
\hline$E$-3,4-Dimethyl-2-pentene & $0.5 *$ & 0.2 & 91.5 & 6.88 & 7.11 & 98,83 \\
\hline 1-Heptene & 0.5 & 0.2 & 93.6 & 6.89 & 7.48 & 56,70 \\
\hline 2-Ethyl-1-pentene & 0.5 & 0.2 & 94.0 & 6.90 & 7.34 & 98,70 \\
\hline E-3-Methyl-3-hexene & $0.4^{*}$ & 0.1 & 93.5 & 6.95 & 7.21 & 98,69 \\
\hline Z-3-Methyl-3-hexene & $0.3^{*}$ & 0.1 & 95.4 & 6.95 & 7.21 . & 98,69 \\
\hline$E$-3-Heptene & 1.6 & 0.5 & 95.7 & 6.98 & 7.24 & 98,56 \\
\hline$Z$-3-Heptene & 0.8 & 0.2 & 95.8 & 7.01 & 7.45 & 98,56 \\
\hline 2-Methyl-2-hexene & 1.9 & 0.5 & 95.4 & 7.02 & 7.23 & 98,69 \\
\hline Z-3-Methyl-2-hexene & 0.9 & 0.3 & 97.3 & 7.03 & 7.25 & 98,69 \\
\hline$E$-2-Heptene & 1.3 & 0.4 & 97.9 & 7.05 & 7.30 & 98,56 \\
\hline 3-Ethyl-2-pentene & 0.4 & 0.1 & 96.0 & 7.07 & $7.25 *$ & 98,69 \\
\hline E-3-Methyl-2-hexene & 1.2 & 0.3 & 95.2 & 7.09 & 7.25 & 98,69 \\
\hline$Z$-2-Heptene & 0.8 & 0.2 & 98.4 & 7.12 & 7.51 & 98,56 \\
\hline 2,3-Dimethyl-2-pentene & 0.5 & 0.1 & 97.4 & 7.13 & 7.11 & 98,83 \\
\hline
\end{tabular}




\begin{tabular}{|c|c|c|c|c|c|c|}
\hline \multirow{2}{*}{ Alkenes } & \multicolumn{2}{|c|}{ Relative proportions } & \multirow{2}{*}{$\begin{array}{l}\text { Boiling } \\
\text { point } \\
{ }^{\circ} \mathrm{C} \\
\end{array}$} & \multicolumn{2}{|c|}{ Relative retentions } & \multirow{2}{*}{$\begin{array}{c}\text { Specific } \\
\text { MS ions } \\
m / z\end{array}$} \\
\hline & $\begin{array}{l}\text { Liquid } \\
\%\end{array}$ & $\begin{array}{l}\text { Gas } \\
\%\end{array}$ & & $\begin{array}{c}\text { Methylsilicone } \\
\text { MU }\end{array}$ & $\begin{array}{c}\mathrm{Al}_{2} \mathrm{O}_{3} / \mathrm{KCl} \\
M U\end{array}$ & \\
\hline Cycloalkenes & 14.7 & 6.1 & & & & \\
\hline \multicolumn{7}{|l|}{ C5 } \\
\hline Cyclopentene & 2.1 & 2.2 & 44.2 & 5.48 & 5.26 & 68,67 \\
\hline \multicolumn{7}{|l|}{ C6 } \\
\hline 3-Methylcyclopentene & 1.0 & 0.5 & 64.9 & 6.08 & $6.13^{*}$ & 82,67 \\
\hline 4-Methylcyclopentene & 0.5 & 0.3 & 65.7 & 6.11 & $6.13^{*}$ & 82,67 \\
\hline 1-Methylcyclopentene & 4.2 & 1.6 & 75.5 & 6.48 & 6.13 & 82,67 \\
\hline Cyclohexene & 0.6 & 0.2 & 83.0 & 6.73 & 6.39 & 82,54 \\
\hline \multicolumn{7}{|l|}{$\mathbf{C 7}$} \\
\hline 1,3-Dimethylcyclopentene & 1.2 & 0.2 & 92 & 6.98 & 6.86 & 96,81 \\
\hline 1,4-Dimethylcyclopentene & 1.0 & 0.3 & 93.2 & 7.00 & $6.92^{*}$ & 96,81 \\
\hline 1,5-Dimethylcyclopentene & 0.9 & 0.2 & 102 & 7.06 & $6.90 *$ & 96,81 \\
\hline 1,2-Dimethylcyclopentene & 2.0 & 0.4 & 105.8 & 7.10 & 6.86 & 96,81 \\
\hline 1-Ethylcyclopentene & 0.5 & 0.1 & 106.3 & 7.52 & 7.05 & 96,67 \\
\hline 1-Methylcyclohexene & 0.7 & 0.1 & 110.3 & 7.67 & 7.14 & 96,81 \\
\hline
\end{tabular}

* The composition is given as percent of the sum of the 63 alkenes. Uncertain data are marked by an asterisk. Boiling point data are given according to the TRC (Thermodynamics Center, Texas) Thermodynamic Tables. Additional dimethylcyclopentene isomers sum up to $0.5 \%$. The two most prominent $\mathrm{C}_{8}$ alkenes were found to be 1,2,3-trimethylcyclopentene and 1,2,4-trimethylcyclopentene, each amounting to $1 \%$ of total $\mathrm{C}_{5}-\mathrm{C}_{7}$ alkenes in the liquid phase.
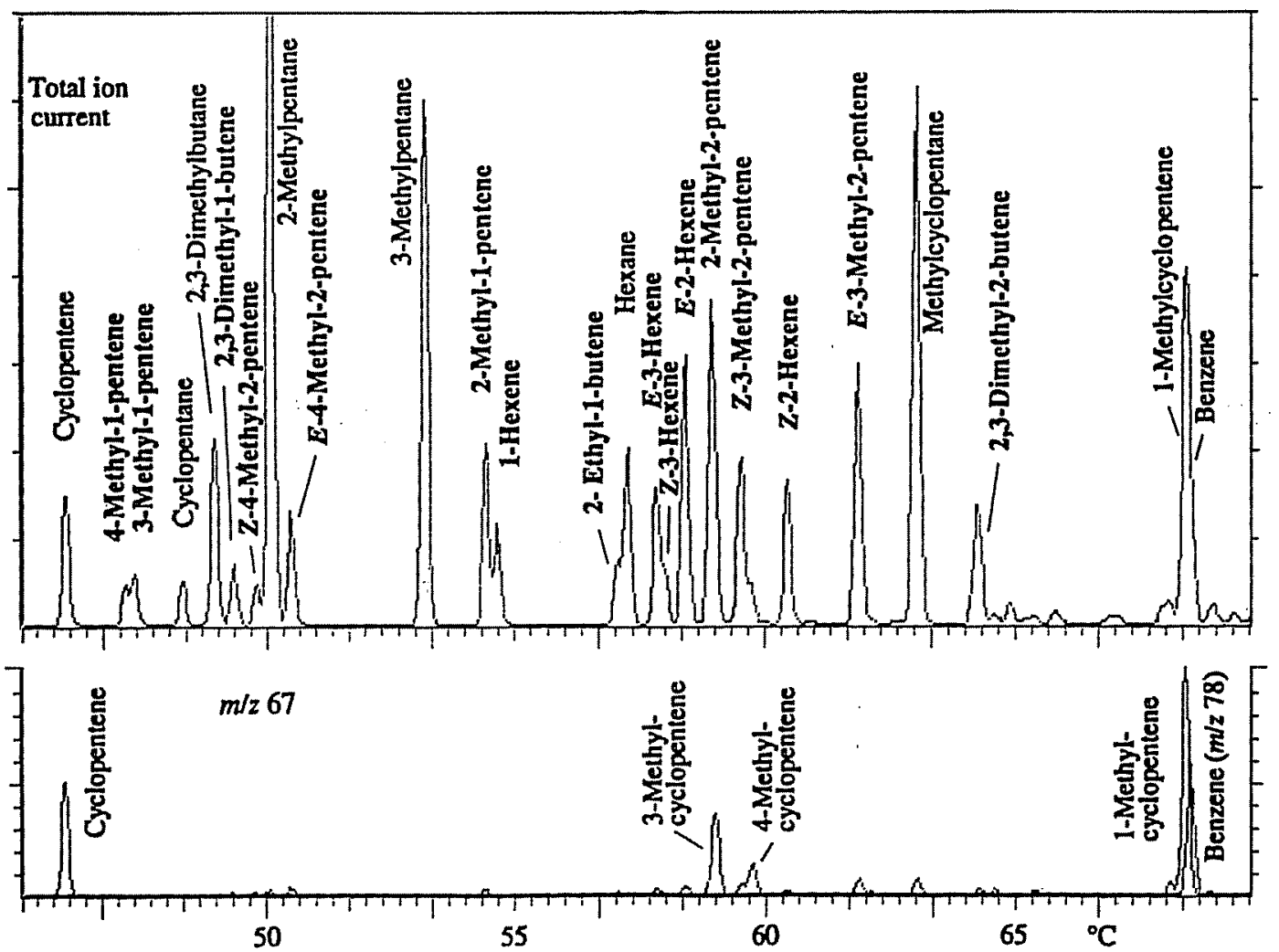

Figure 1

Separations (methylsilicone column) and hydrocarbon identities in the hexene range of the FCC naphtha; total ion chromatogram with 16 acyclic hexenes; single-ion chromatograms marking the incompletely resolved methylcyclopentenes $(\mathrm{m} / \mathrm{z} 67, \mathrm{M}-15)$ and benzene $(\mathrm{m} / \mathrm{z} 78, \mathrm{M})$. 